\title{
Comparison of Complications and Efficacy of NIPPV and Nasal CPAP in Preterm Infants With RDS
}

\author{
Tahereh Esmaeilnia,' Fatemeh Nayeri, ${ }^{1}$ Roya Taheritafti, ${ }^{1, *}$ Mamak Shariat, ${ }^{1}$ and Faezeh \\ Moghimpour-Bijani ${ }^{2}$ \\ ${ }_{1}^{1}$ Maternal Fetal and Neonatal Research Center, Tehran University of Medical Sciences, Tehran, IR Iran \\ 2 Department of Pediatrics, Imam Khomeini Hospital, Tehran University of Medical Sciences, Tehran, IR Iran \\ ${ }^{*}$ Corresponding author: Roya Taheritafti, Maternal Fetal and Neonatal Research Center, Tehran University of Medical Sciences, Tehran, IR Iran. Tel:+98-9126188148, Fax:+98-2188484577, \\ E-mail: royataheritafti@yahoo.com
}

Received 2015 May 18; Revised 2015 November 8; Accepted 2015 December 9

\begin{abstract}
Background: Respiratory distress syndrome (RDS) is one of the most common diseases in neonates admitted to NICU. For this important cause of morbidity and mortality in preterm neonates, several treatment methods have been used. To date, non-invasive methods are preferred due to fewer complications.

Objectives: Herein, two non-invasive methods of ventilation support are compared: NCPAP vs. NIPPV.

Patients and Methods: This is a randomized clinical trial. Premature neonates with less than 34 weeks gestation, suffering from RDS entered the study, including 151 newborns admitted to Vali-Asr NICU during 2012-2013. Most of these patients received surfactant as early rescue via INSURE method and then randomly divided into two NCPAP (73 neonates) and NIPPV (78 neonates) groups. Both early and late complications are compared including extubation failure, hospital length of stay, GI perforation, apnea, intraventricular hemorrhage (IVH) and mortality rate.

Results: The need for re-intubation was $6 \%$ in NIPPV vs. $17.6 \%$ in NCPAP group, which was statistically significant $(\mathrm{P}=0.031)$. The length of hospital stay was $23.92 \pm 13.5$ vs. $32.61 \pm 21.07$ days in NIPPV and NCPAP groups, respectively $(\mathrm{P}=0.002)$. Chronic lung disease (CLD) was reported to be $4 \%$ in NCPAP and $0 \%$ in NIPPV groups $(\mathrm{P}=0.035)$. The most common complication occurred in both groups was traumatization of nasal skin and mucosa, all of which fully recovered. Gastrointestinal perforation was not reported in either group. Conclusions: This study reveals the hospital length of stay, re-intubation and BPD rates are significantly declined in neonates receiving NIPPV as the treatment for RDS.
\end{abstract}

Keywords: Respiratory Distress Syndrome, Prematurity, NIPPV, NCPAP

\section{Background}

Respiratory distress syndrome (RDS) is the most common respiratory disease in premature neonates with low birth weight (1). Congenital surfactant deficiency is among the etiologies, as well. Surfactant insufficiency leads to alveolar collapse and multiple micro-atelectasis. To provide sufficient Functional Residual Capacity (FRC), surfactant administration and mechanical ventilation are utilized. However, tracheal intubation and long term mechanical ventilation increase the risk of pneumothorax, respiratory infections and trauma (e.g. barotrauma, volutrauma) (2). Despite brilliant improvements in treatment of newborns with RDS, controversies exist in defining the most effective method and investigations with the lowest complications are still necessary (3). The most recent guideline published in 2013 suggests using nasal ventilation as the first step, even before surfactant administration (3).

On the other hand, NCPAP is approved as a method of ventilation support in neonates with $\operatorname{RDS}(4,5)$. Al- though it reduced the need for intubation in premature neonates $(6,7)$, it is failure rate is reported as high as 15 $50 \%(8,9)$. Thus, using a non-invasive method with lower failure rates seems reasonable. NIPPV increases minute ventilation and tidal volume in comparison to NCPAP (10). Moreover, extubation failure rate was lower, as well $(11,12)$. NIPPV is able to use PIP in addition to appropriate PEEP to utilize more alveoli, which is very valuable (13). Besides, PEEP can be set lower in NIPPV.

NCPAP and NIPPV are both continued distending pressure (CDP) methods. They improve diaphragm function, increase pulmonary compliance and reduce upper and lower airways resistance. What's more, tidal volume and compliance increase, whereas alveolar edema declines.

\section{Objectives}

Herein, complications and benefits of these two noninvasive methods are compared.

Copyright @ @ 2016, Growth \& Development Research Center. This is an open-access article distributed under the terms of the Creative Commons Attribution-NonCommercial 4.0 International License (http://creativecommons.org/licenses/by-nc/4.0/) which permits copy and redistribute the material just in noncommercial usages, provided the original work is properly cited. 


\section{Patients and Methods}

This study is a randomized clinical trial. Newborns with RDS and gestational age $<34$ weeks admitted to NICU in Vali-Asr hospital, Tehran, Iran during 2012-2013 were enrolled in the study, consisting of 151 neonates with respiratory score (8) between 5-8. Informed consent was taken from the guardians. This study was approved by the institutional research ethics committee of Tehran University of Medical Sciences (Ethics code: 12046-91-04-89). Infants were excluded for any of the following reasons: major congenital anomalies, presence of cardiovascular instability and intubation at admission to the NICU, consent not provided or refused and asphyxia (Apgar $\leq 3, \mathrm{BE} \geq$ -12 , multiple organ failure). Thirty-five of totally 151 newborns in this study received noninvasive ventilation as a primary mode (without surfactant therapy); 18 infants received NCPAP and 17 infants received NIPPV randomly.
$13(72 \%)$ infants of NIPPV group cured without surfactant therapy and only 4 (28\%) infants needed surfactant therapy as INSURE, all of them again received NIPPV after INSURE and cured. In NCPAP group as primary mode $8(44 \%)$ infants cured without surfactant therapy and 10 (56\%) infants needed surfactant therapy.

In remaining infants surfactant was administered via INSURE method and then, they randomly (via block randomization) were divided into NCPAP (73 cases) and NIPPV (78 cases) group (Figure 1). Both groups received Survanta $100 \mathrm{mg} / \mathrm{kg} /$ dose with INSURE technique. Early (primary) complications including, re-intubation, pneumothorax, GI perforation, apnea, IVH and mortality rates were compared. Secondary outcomes compared were chronic lung disease (CLD) and length of hospital stay. To display the result graphically, Kaplan-Meier curves were plotted.

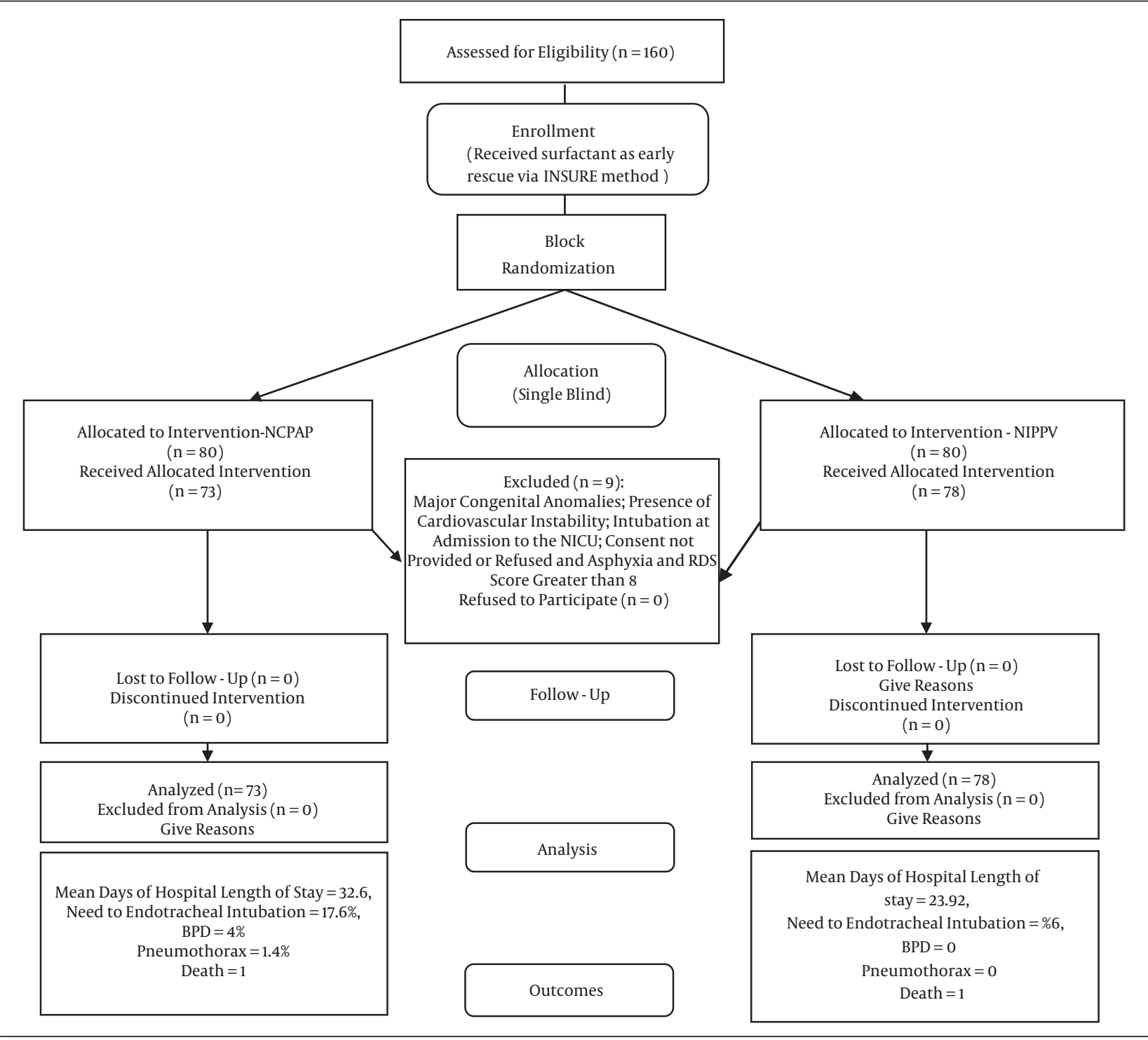

Figure 1. The Consort Flowchart 


\section{Results}

Demographic parameters did not differ significantly among NCPAP and NIPPV group (Table 1). The difference of pneumothorax, apnea, GI perforation and mean duration of ventilation support between the two groups was not statistically significant. Also the difference of intraventricular hemorrhage (IVH) was not statistically significant, IVH occurred less common and less severe in NIPPV group. IVH was detected in 10 (13.7\%) neonates in NCPAP and 7 (9\%) in NIPPV group, which was not statistically different. Eighty percent of IVH cases in NCPAP group were of grade 1-2 and twenty percent of grade 3-4. However, in NIPPV group $86 \%$ of IVH cases had grade $1-2$ and $14 \%$ were in grade $3-4$. The need for intratracheal intubation in first 72 hours was statistically significant between the two groups (17.6\% in NCPAP vs. $6 \%$ in NIPPV, P = 0.031). The difference of CLD was statistically significant ( $4 \%$ in NCPAP group vs. no case in NIPPV group. $\mathrm{P}=0.035$ ). Duration of hospitalization was $23.92 \pm 13.5$ and $32.61 \pm$ 21.07 days in NIPPV and NCPAP group, respectively. The difference was statistically significant $(P=0.003)$ (Figure 2 and Table 1). Re-intubation rate in the first 72 hours in NCPAP group was 13 (17.6\%) occasions and in NIPPV group it was $5(6 \%)$ occasions which was significantly higher in NCPAP group (OR: 1.67, CI:1.13, P = 0.003) (Table 2 and Figure 3 ).

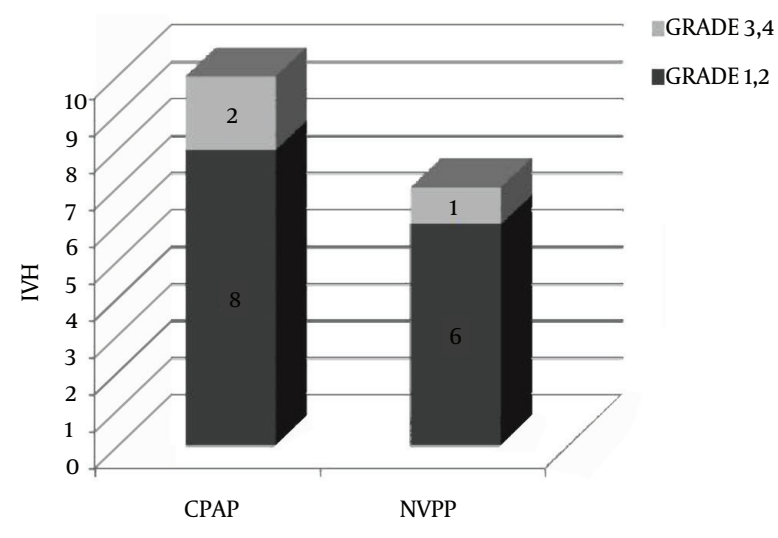

Figure 2. Incidence of IVH in CPAP and NIPPV

Table 1. Demographic Parameters ${ }^{\mathrm{a}}$

\begin{tabular}{lccc}
\hline Variables & NCPAP $(\mathbf{n}=\mathbf{7 3})$ & NIPPV $(\mathbf{n}=77)$ & P Value \\
\hline Gender & & & 0.371 \\
\hline Male & $39(53.5)$ & $36(46)$ & \\
\hline Female & $34(46.5)$ & $42(54)$ & 0.916 \\
\hline Birth weight, gr & $1627 \pm 539$ & $1637 \pm 631$ & 0.80 \\
\hline Gestational age, wk & $32.15 \pm 2.03$ & $32.04 \pm 2.91$ & 0.055 \\
\hline Birth length, cm & $36.98 \pm 14$ & $41.18 \pm 6.5$ & 0.650 \\
\hline Head circumference, cm & $28.65 \pm 5.91$ & $29.01 \pm 3.17$ & 0.733 \\
\hline Apgar 1, min & $6.86 \pm 2.14$ & $6.97 \pm 1.84$ & 0.358 \\
\hline Apgar 5, min & $8.28 \pm 1.12$ & $8.07 \pm 1.64$ & 0.020 \\
\hline Apgar 20, min & $7.98 \pm 2.26$ & $7.87 \pm 2.50$ & 0.180 \\
\hline Antenatal steroids received & $53(73.3)$ & $64(83.3)$ & 0.130 \\
\hline Born by cesarean section & $51(70)$ & $62(81.7)$ & \\
\hline
\end{tabular}

${ }^{\mathrm{a}}$ Values are expressed as No. (\%) or mean \pm SD.

\begin{tabular}{lccc}
\hline Table 2. Complications $^{\mathrm{a}}$ & & & \\
\hline Complication & NCPAP & NIPPV & P Value \\
\hline Death & $1(1.3)$ & $1(1.4)$ & 0.947 \\
Pneumothorax & $1(1.4)$ & 0 & 0.316 \\
NEC & 0 & 0 & NA \\
Apnea & $3(4)$ & $1(1.3)$ & 0.280 \\
IVH & $10(14)$ & $7(9)$ & 0.389 \\
CLD & $3(4)$ & 0 & 0.035 \\
Re-intubation & $13(18)$ & $5(6.5)$ & 0.031 \\
Length of hospital & $32.61 \pm 21.07$ & $23.92 \pm 13.5$ & 0.003
\end{tabular}


Esmaeilnia T et al.

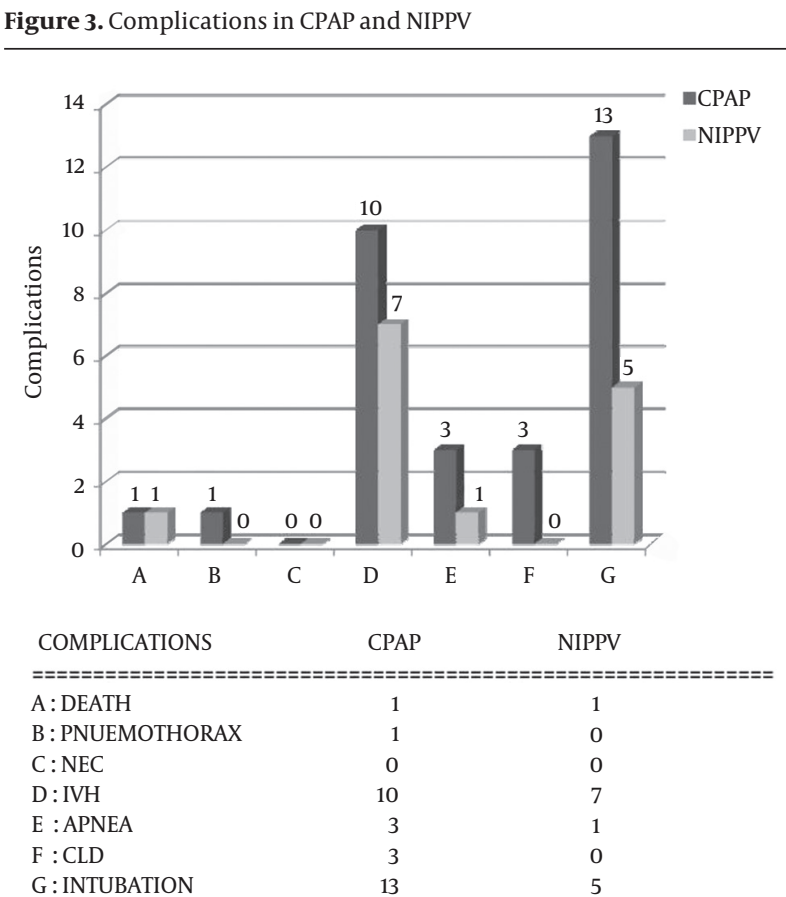

A, Death; B, Pneumothorax; C, NEC; D) IVH; E, Apnea; F,CLD; G,Intubation.

\section{Discussion}

There are several common points in this study with previous studies; however, there are some differences which are discussed. Re-intubated cases in first 72 hours were $5(6 \%)$ in NIPPV vs. 13 (17.6\%) in NCPAP group, which is statistically significant. Regarding re-intubation complications, this study found NIPPV as a feasible method. Extubation failure was defined as hypercapnia $\left(\mathrm{pCO}_{2}>\right.$ 60 ), need to a PEEP $>6-7$, need to PIP $>20, \mathrm{pH}<7.2$ and recurrent apnea. Tang et al. reported a lower incidence of endotracheal intubation in NIPPV group (14). Davis et al. (13) and Bahman-Bijari et al. (12) found similar results. NIPPV reduces the need for high PEEP and provides higher functional residual capacity (FRC). More alveoli are utilized in this method because of using higher peak inspiratory pressure (PIP). Besides, respiratory muscles' work decreases.

This study did not detect significant difference in pneumothorax incidence between the two groups. The same is reported by Meneses et al. (15). However, this parameter was not investigated in some other studies $(12,13)$. Using the least possible PEEP in NCPAP group may explain it. Sometimes in NCPAP mode, to reach $\mathrm{O}_{2}$ saturation $>90 \%$, PEEP parameters higher than $6 \mathrm{~cm} \mathrm{H}_{2} \mathrm{O}$ for newborns have to be used. These high PEEP parameters may cause pneumothorax. If we were allowed to use higher PEEP parameters in our study, we might have detected significant differences in pneumothorax incidence in both groups as evidenced in neonatal literature. Besides, using PIP in
NIPPV group mandates lower PEEP to achieve sufficient ventilation. Here apnea rate did not differ significantly between the two groups (4\% in NCPAP vs. $1.3 \%$ in NIPPV). Barrington et al. reported a lower rate of apnea in NIPPV group which was not statistically significant (10). After all, apnea has not been reported to be higher in newborns cared with NIPPV. CLD was 2.1 folds higher in NCPAP vs. NIPPV group in our study which was a significant $(\mathrm{P}=$ 0.035) difference. The diagnosis was made due to clinical, laboratory and radiologic findings (16). Similar results were reported by other studies (10-12). Tang et al. reported a lower rate of CLD in NIPPV vs. NCPAP group, as well (14). Meneses et al. did not report a significant difference in CLD rate between the two groups (15). This may be due to different inclusion criteria. They had included in their study also neonates with low Apgar score at birth and those who received CPR and PPV. Consequently, these patients had developed pulmonary insults before receiving ventilation support. Therefore, CLD incidence was not different significantly between the two groups. Mean birth weight of their patients was $1100 \mathrm{gr}$ in comparison to $1600 \mathrm{gr}$ in this study. Therefore, some cases with low Apgar score and probable asphyxia had entered Meneses' study, which might have affected the outcomes. For instance, BPD incidence was reported to be as high as $25 \%$ which is not reported elsewhere (15).

This study found a significant shorter hospitalization duration in NIPPV group $(\mathrm{P}=0.003)$. Kaplan Mayer survival curve and regression test have confirmed this finding. This reveals NIPPV as a potential method to decrease expenses. Bahman-Bijari et al. reported a similar result (12). Meneses et al. reported no difference (15). Davis et al. did not find a significant difference. However, NIPPV was used in cases of NCPAP failure in this study, which was ignored in statistical analysis (13).

We found a higher incidence of IVH in NCPAP group, though not statistically significant. A randomized clinical trial performed by Bhandari et al. reported no difference between the two groups (17). We did not find a higher incidence of IVH in infants assisted with NIPPV in our cases.

This study detects no case of NEC or GI perforation in the two groups. Utilizing a F8 OG tube prevents abdominal distention. Besides, appropriate nursing care is crucial in careful measurement of the tube length and its fixation. Similar results were reported by Davis and coworkers (13), and Meneses et al. (15). Older studies have reported some cases of NEC and GI perforation, using NCPAP (18). However, Davis et al. and Lemyre et al. did not confirm this association $(13,19)$. Regarding all that, appropriate OG size is recommended in NCPAP use to prevent CPAP gastrointestinal complications.

Average time of ventilation support did not differ significantly between the two groups in our study. Meneses et al. published similar results (15). Nonetheless, BahmanBijari et al. (12) and Ramanathan et al. (20) reported significantly shorter duration of ventilation in NIPPV group. 
A probable explanation may be the difference in weaning criteria. Our criteria for weaning included: normal ABG, absence of respiratory distress, stable vital signs, no reduction in oxygen saturation, absence of apnea and spontaneous effective respiration by the neonate. Then, the infant was weaned and cared under oxyhood with 5 $\mathrm{L} / \mathrm{min}$ flow rate. In the case of normal oxygen saturation, chest X-ray, vital signs and general condition, the oxyhood was removed. Weaning criteria in Bahman-Bijari et al. study were respiratory rate between $30-60, \mathrm{FiO}_{2}<30 \%$, $\mathrm{O}_{2}$ sat $>90 \%$ and PEEP $<5$ (12).

Traumatization of the skin around nose and mouth and irritation of nasal mucosa occurred in both groups. Yet, all of them recovered after weaning without any complication. Appropriate nursing care is fundamental in this field. Lower rates of barotraumas and air leak were found in this study.

Synchronization of NIPPV is focused in recent studies. This needs special skin sensors that are not available in Iran. Utilizing synchronized NIPPV (SNIPPV) revealed more successful results. A signal detector sensitive to abdominal motion is necessary for this method. It synchronizes ventilation support with infant's thoraco-abdominal motions. What can be done instead is setting a ventilator setup similar to patient's respiration efforts. However, Dumpa et al. reported no benefit for SNIPPV compared with NIPPV. No difference with PDA, IVH, BPD, ROP, PVL and mortality rates was significant. This confirms NIPPV as an effective method with least complications (21).

We found NIPPV to be more efficient compared with NCPAP in the management of RDS. Reduced length of hospital stay, lesser need to endotracheal intubation, and decreased BPD incidence are among the advantages which can totally reduce health care expenses $(22,23)$.

\section{References}

1. Dunn MS, Reilly MC. Approaches to the initial respiratory management of preterm neonates. Paediatr Respir Rev. 2003;4(1):2-8. [PubMed:12615026]

2. Owen LS, Morley CJ, Davis PG. Neonatal nasal intermittent positive pressure ventilation: a survey of practice in England. Arch Dis Child Fetal Neonatal Ed. 2008;93(2):F148-50. doi: 10.1136| adc.2007.118109. [PubMed:17875576]

3. Verder H. Nasal CPAP has become an indispensable part of the primary treatment of newborns with respiratory distress syndrome. Acta Paediatr. 2007;96(4):482-4. doi: 10.1111/j.16512227.2007.00263.x. [PubMed:17391463]

4. Gittermann MK, Fusch C, Gittermann AR, Regazzoni BM, Moessinger AC. Early nasal continuous positive airway pressure treatment reduces the need for intubation in very low birth weight infants. Eur J Pediatr. 1997;156(5):384-8. [PubMed: 9177982]

5. De Klerk AM, De Klerk RK. Nasal continuous positive airway pressure and outcomes of preterm infants. J Paediatr Child Health. 2001;37(2):161-7. [PubMed:11328472]

6. Reininger A, Khalak R, Kendig JW, Ryan RM, Stevens TP, Reubens L, et al. Surfactant administration by transient intubation in infants 29 to 35 weeks' gestation with respiratory distress syndrome decreases the likelihood of later mechanical ventilation: a randomized controlled trial. J Perinatol. 2005;25(11):703-8. doi: 10.1038/sj.jp.7211381. [PubMed:16163369]
7. Fanaroff A, Martin R. Assisted ventilation and its complications. 9th ed. USA: Elsevier Mosby; 2011. Neonatal-Perinatal Medicine Disease of the Fetus and Infant. p. 11.

8. Goldsmith JP, Karotkin EH, Barker S. Assisted ventilation of the neonate. Philadelphia: Saunders; 2011. pp. 140-62.

9. Friedlich P, Lecart C, Posen R, Ramicone E, Chan L, Ramanathan R. A Randomized Trial of Nasopharyngeal-Synchronized Intermittent Mandatory Ventilation Versus Nasopharyngeal Continuous Positive Airway Pressure in Very Low Birth Weight Infants After Extubation. J Perinatol. 1999;19(6):413-8. doi: 10.1038/ sj.jp.7200205. [PubMed:10685270]

10. Barrington KJ, Bull D, Finer NN. Randomized trial of nasal synchronized intermittent mandatory ventilation compared with continuous positive airway pressure after extubation of very low birth weight infants. Pediatrics. 2001;107(4):638-41. [PubMed: 11335736]

11. Khalaf MN, Brodsky N, Hurley J, Bhandari V. A prospective randomized, controlled trial comparing synchronized nasal intermittent positive pressure ventilation versus nasal continuous positive airway pressure as modes of extubation. Pediatrics. 2001;108(1):13-7. [PubMed:11433048]

12. Bahman-Bijari B, Mahdian R, Niknafs P, Baneshi MR. Nasal Intermittent Positive Pressure Ventilation vs Nasal Continuous Positive Pressure in Preterm Infants with Respiratory Distress. Zahedan J Res Med Sci . 2014;16(11):9-14.

13. Davis PG, Lemyre B, De Paoli AG, Davis PG. Nasal intermittent positive pressure ventilation (NIPPV) versus nasal continuous positive airway pressure (NCPAP) for preterm neonates after extubation. Cochrane Database Syst Rev. 2001;(3):CD003212. doi: 10.1002/14651858.cd003212.

14. Tang S, Zhao J, Shen J, Hu Z, Shi Y. Nasal intermittent positive pressure ventilation versus nasal continuous positive airway pressure in neonates: A systematic review and meta-analysis. Indian Ped J. 2013;50(4):371-6. doi:10.1007/s13312-013-0122-0.

15. Meneses J, Bhandari V, Alves JG, Herrmann D. Noninvasive ventilation for respiratory distress syndrome: a randomized controlled trial. Pediatrics. 2011;127(2):300-7. doi: 10.1542/peds.20100922. [PubMed: 21262883]

16. Fanaroff A, Martin R. Neonatal-Perinatal medicine disease of the fetus and Infant. 9 th ed. USA: Elsevier Mosby; 2011.

17. Bhandari V, Gavino RG, Nedrelow JH, Pallela P, Salvador A, Ehrenkranz RA, et al. A randomized controlled trial of synchronized nasal intermittent positive pressure ventilation in RDS. $J$ Perinatol. 2007;27(11):697-703. doi:10.1038/sj.jp.7211805. [PubMed: 17703184]

18. Garland JS, Nelson DB, Rice T, Neu J. Increased risk of gastrointestinal perforations in neonates mechanically ventilated with either face mask or nasal prongs. Pediatrics. 1985;76(3):406-10. [PubMed: 4034300]

19. Lemyre B, Davis PG, de Paoli AG. Nasal intermittent positive pressure ventilation (NIPPV) versus nasal continuous positive airway pressure (NCPAP) for apnea of prematurity. Cochrane Database Syst Rev. 2002;(1):CD002272. doi:10.1002/14651858.CD002272. [PubMed: 11869635]

20. Ramanathan R, Sekar KC, Rasmussen M, Bhatia J, Soll RF. Nasal intermittent positive pressure ventilation after surfactant treatment for respiratory distress syndrome in preterm infants $<30$ weeks' gestation: a randomized, controlled trial. I Perinatol. 2012;32(5):336-43. doi:10.1038/jp.2012.1. [PubMed: 22301528]

21. Dumpa V, Katz K, Northrup V, Bhandari V. SNIPPV vs NIPPV: does synchronization matter? J Perinatol. 2012;32(6):438-42. doi: 10.1038/jp.2011.117. [PubMed: 22116527]

22. Sweet DG, Carnielli V, Greisen G, Hallman M, Ozek E, Plavka R, et al. European consensus guidelines on the management of neonatal respiratory distress syndrome in preterm infants-2013 update. Neonatology. 2013;103(4):353-68. doi: 10.1159/000349928. [PubMed: 23736015]

23. Davis PG, Morley CJ, Owen LS. Noninvasive respiratory support of preterm neonates with respiratory distress: Continuous positive airway pressure and nasal intermittent positive pressure ventilation. Semin Fetal Neonatal Med . 2008;10(1):14-20. [PubMed: 18835546] 